27 Schonfeld G, Birge C, Miller JP, Kessler G, Santiago J. Apolipoprotein B levels and altered lipoprotein composition in diabetes. Diabetes 1974;23: 827-34.

28 Uusitupa $\mathrm{M}$, Siitonen $\mathrm{O}$, Voutilainen $\mathrm{E}$, et al. Serum lipids and lipoproteins in newly diagnosed non-insulin-dependent (type II) diabetic patients with special reference to factors influencing HDL-cholesterol and triglyceride special reference to factors influe
levels. Diabetes Care 1986;9:17-22.

29 Howard BV, Knowler WC, Vasquez B, Kennedy AL, Pettitt DJ, Bennett PH. Plasma and lipoprotein cholesterol and triglyceride in the Pima Indian population. Comparison of diabetics and non-diabetics. Arteriosclerosis 1984;4:462-71.

30 Betteridge DJ. Diabetes, lipoprotein metabolism and atherosclerosis. $\mathrm{Br} \mathrm{Med}$ Bull 1989;45:285-311.

31 Keen H, Jarrett RJ. The WHO Multinational Study of Vascular Disease in $187-95$ trial with gemfbroil in middleaged men wirh dylipidemia. Safery of tral with gemfibrozil in

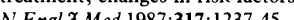

33 Blankenhorn DH, Nessim SA, Johnson RL, Sanmarco ME, Azen SP, Cashin-Hemphill L. Beneficial effects of combined colestipol-niacin therapy on coronary atherosclerosis and coronary venous bypass grafts. $J A M A$ 987;257:3233-40

34 Garg A, Grundy SM. Treatment of dyslipidemia in non-insulin-dependent diabetes mellitus with lovastatin. Am f Cardiol 1988;62:44-7.

(Accepted 14 August 1989)

\title{
Incidence of peptic ulcer disease in Gothenburg, 1985
}

\author{
Ivi-Mai Schöön, Dan Mellström, Anders Odén, Bengt-Olov Ytterberg
}

Abstract

Objective-To determine the incidence and age distribution of peptic ulcer disease in adults in Gothenburg.

Design-Retrospective study of patients with symptoms over one year.

Setting-All gastroenterology and $x$ ray departments.

Patients-Any patient found to have an active ulcer crater during 1985.

Main outcome measures-Sex, age, past history of gastrointestinal ulcers, and smoking habit.

Results-In 1985, 1402 peptic ulcers were diagnosed in 1137 adults. Over half $(403 ; 54 \%)$ of the ulcers in men and $393(60 \%)$ ulcers in women were in patients aged over 60 . All types of ulcer showed increasing incidence with age. The sex ratio of patients aged 40-50 with peptic ulcers was 1:1. Nearly half $(109 ; 48 \%)$ of ulcers diagnosed for the first time in men and $129(57 \%)$ of such ulcers in women were in patients aged over 60 . Elderly men and women were also more likely to develop haemorrhage.

Conclusions -In Gothenburg there is a surprisingly high incidence of peptic ulcer disease, which increases considerably with age, possibly explained by the availability of modern diagnostic techniques as $1121(80 \%)$ ulcers had been diagnosed by gastroscopy. Compared with earlier studies there was no difference in the incidence between men and women aged 40-50.

\section{Introduction}

During the past 20 years the death rate and rate of

Department of Surgery, Central Clinic, Östra Sjukhuset, S-416 85 Gothenburg, Sweden

Ivi-Mai Schöön, MD, registrar

Clinic V, Vasa Hospital, Gothenburg

Dan Mellström, MD, senior consultant

Bengt-Olov Ytterberg, MD, registrar

\section{Department of}

Mathematics, University of Gothenburg, Gothenburg

Anders Odén, PHD, associate professor

Correspondence to:

Dr Schöön.

BrMed f 1989;299:1131-4 $a l^{13}$ used gastroscopic findings; other investigations are based on $x$ ray diagnosis or inpatient series, or both. In Sweden gastroscopy is the primary means of investigating suspected peptic ulcer, and in $1985,80 \%$ (1121) of all diagnoses of ulcers made in Gothenburg were confirmed by gastroscopy. We investigated the incidence of peptic ulcer disease during a period when decreasing mortality, surgical intervention, and hospital admissions for this condition were reported.

\section{Patients and methods}

The figure of 360042 for the adult population of Gothenburg - that is, people aged over 15-was estimated as the mean of the numbers registered on 31 December 1984 and 31 December 1985. The figures were derived from the local population register of all residents in one year age classes. The population was divided into age groups of five or 10 years for calculation of the age specific incidence. In Gothenburg $1 \cdot 2 \%$ of people aged over 65 and $14 \%$ of men aged 40 are immigrants, most having come from Finland, usually at the age of about 20 . In Sweden all residents belong to the social insurance system, which means that the consumption of medical care is uniformly distributed. Endoscopic methods are therefore widely used in both inpatients and outpatients.

Peptic ulcers diagnosed during 1985 were registered in collaboration with all gastroenterology departments performing gastroscopies and all $x$ ray departments. In 1985 gastroscopy was performed at three major surgical centres, one major department of internal medicine, two smaller hospital departments, and three private practices. Data about all gastroscopies performed in Gothenburg were recorded during the year.

The $x$ ray units equipped with organ specific computerised registers supplied results of all barium meals. Of the 1137 patients with active ulcer craters, 1013 were interviewed by telephone about earlier episodes of ulcers, other relevant disease, and smoking habits. The relations between smoking habits among the population as a whole and the patients with peptic ulcer of the present study will be presented in a separate paper.

Hospital records of patients with perforated or bleeding ulcers diagnosed at an emergency operation without previous gastroscopy were collected during the year from the two hospitals with casualty departments. Patients found to have no ulcer crater at the time of operation were excluded. Gastric ulcers were defined as ulcers near to or proximal to the gastric angulus; prepyloric ulcers as ulcers on the gastric side of the pylorus or within $3 \mathrm{~cm}$ proximal to the pylorus; and duodenal ulcers as ulcers located in the duodenal bulb or on the distal part of the pyloric valve. 
The ethics committee of the department of medicine, University of Gothenburg, and the data inspection board consented to inspection of the patients' records.

\section{Statistical methods}

The maximum likelihood estimates of the risk ratios (women to men) were determined for age intervals of 20 years without assuming a constant risk within the intervals. Confidence intervals of the ratios were calculated by applying the duality between tests and confidence sets on the optimal test for comparing Poisson distributions. ${ }^{14}$ The correlation between age and presence of haemorrhage within the group with peptic ulcers was tested for trend by contingency tables ${ }^{15}$ with the Edgeworth expansion for the approximation of the $p$ value. ${ }^{16}$ The two sided test was used.

\section{Results}

During 1985, 1402 peptic ulcers were diagnosed in 1137 adults (table I). Only active ulcer craters were registered. A total of $403(54 \%)$ of the ulcers in men and

TABLE I-Diagnoses of peptic ulcers in Gothenburg, 1985

\begin{tabular}{lcc}
\hline Method of diagnosis & No of ulcers & No of patients \\
\hline Gastroscopy & 1121 & 876 \\
Emergency operation & 64 & 64 \\
Barium meal & 217 & 197 \\
\hline Total & 1402 & 1137
\end{tabular}

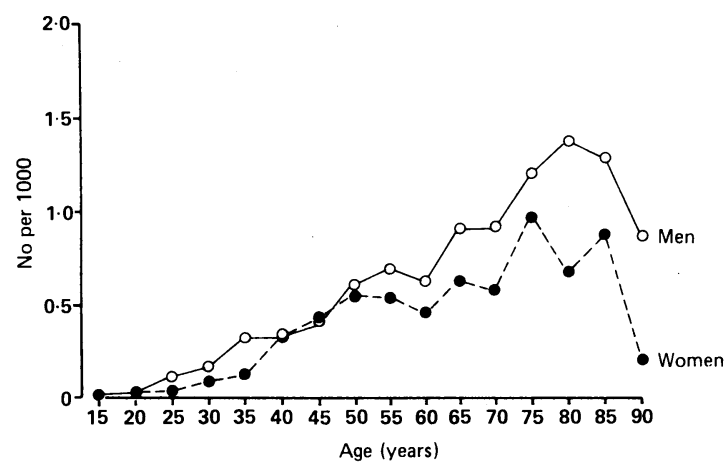

FIG 1-Active peptic ulcers per 1000 inhabitants $(747$ men, 655 women)

TABLE II-Maximum likelihood estimates of risk ratios for peptic ulcers in men and women

\begin{tabular}{ccc}
\hline Age interval (years) & $\begin{array}{c}\text { Risk ratio of peptic ulcer, } \\
\text { men:women }\end{array}$ & $\begin{array}{c}95 \% \text { Confidence } \\
\text { interval }\end{array}$ \\
\hline $15-$ & 0.55 & 0.34 to 0.84 \\
$35-$ & 0.84 & 0.67 to 1.03 \\
$55-$ & 0.70 & 0.59 to 0.83 \\
$\geqslant 75$ & 0.66 & 0.52 to 0.83
\end{tabular}

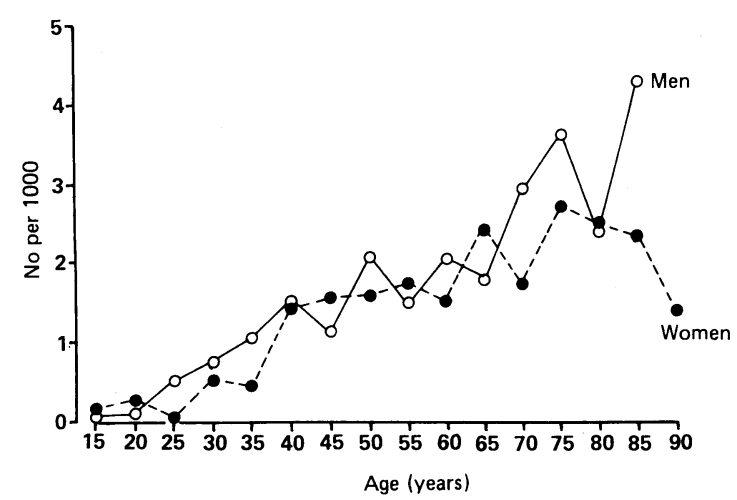

FIG 2-Peptic ulcer diagnosed for first time per 1000 inhabitants (227 men, 227 women)

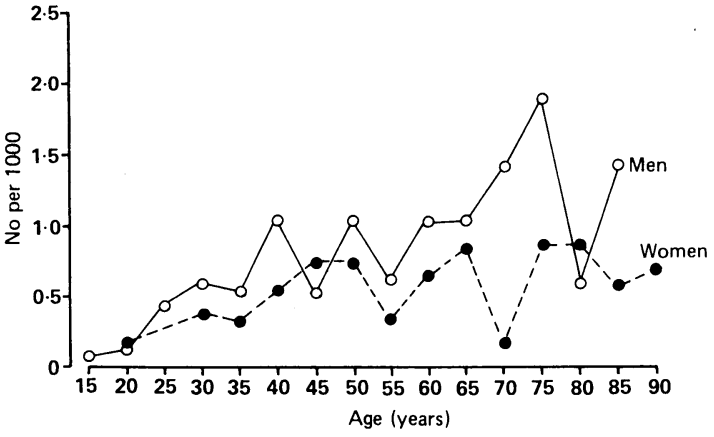

FIG 3-Duodenal ulcer diagnosed for first time per 1000 inhabitants (122 men, 81 women)

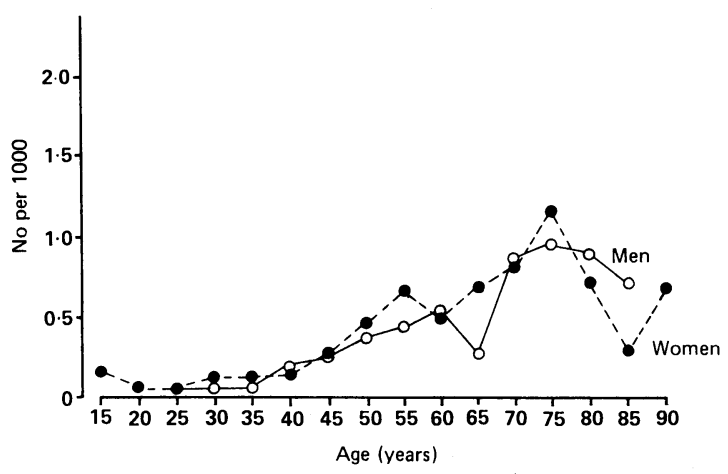

FIG 4-Gastric ulcer diagnosed for first time per 1000 inhabitants (46 men, 71 women)

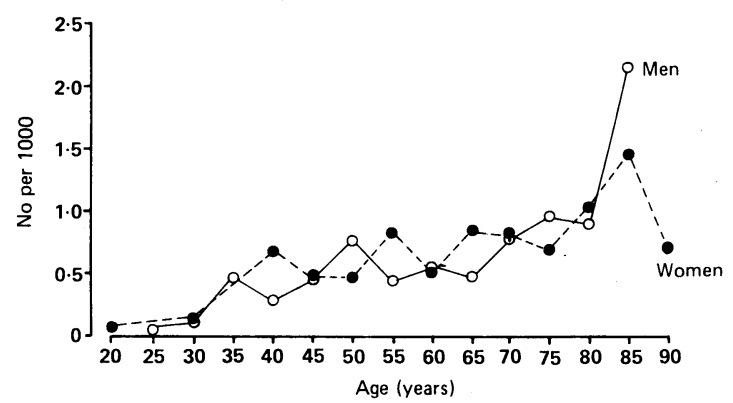

FIG 5-Prepyloric ulcer diagnosed for first time per 1000 inhabitants (64 men, 80 women)

$393(60 \%)$ of those in women affected patients aged over 60 . In 925 patients the diagnosis was made in the outpatient department. The occurrence of peptic ulcer in five year age groups showed a distinct increase with increasing age in both men and women (fig 1). In patients aged 40-50 the ratio of men to women was $1: 1$. Table II gives the maximum likelihood estimates of the risk ratios for women to men. Peptic ulcers were diagnosed for the first time in 454 patients. Figure 2 shows the age and sex distribution of peptic ulcers per 1000 inhabitants, the number per 1000 being calculated with the denominator including people with previous ulcers. The number was about twice as high among men as among women aged 35-39 (fig 2), but in patients aged 40-50 years there was no difference between the sexes. Figures 3, 4, and 5 show the distribution according to age and sex of different types of new ulcer. A total of 563 duodenal ulcers, 413 prepyloric ulcers, and 403 gastric ulcers were diagnosed. In 11 cases duodenal and gastric ulcers were diagnosed simultaneously. The number of cases of perforation during 1985 was 27; all were treated by emergency operation.

Postoperative recurrence took place in 159 of the 1137 patients ( 97 men, 62 women); 61 had previously been treated by gastric resection and 98 by vagotomy, as a rule proximal gastric vagotomy. Table III shows the distribution of bleeding complications. The risk of haemorrhage, possibly dependent on increasing age, 
was deduced from computerised data. By using the test for trend in contingency tables ${ }^{1516}$ we showed significantly higher risk $(\mathrm{p}<0.001)$ of bleeding, increasing with age in both men and women.

TABLE III - Distribution of bleeding among patients with peptic ulcers in Gothenburg, 1985

\begin{tabular}{cccccc}
\hline & \multicolumn{2}{c}{ Total No with peptic ulcers } & & \multicolumn{2}{c}{ No with bleeding } \\
\cline { 2 - 3 } \cline { 5 - 6 } Age (years) & Women & Men & & Women & Men \\
\hline $15-$ & 7 & 7 & & & \\
$25-$ & 17 & 45 & & 2 & 8 \\
$35-$ & 53 & 81 & & 2 & 13 \\
$45-$ & 85 & 95 & & 8 & 13 \\
$55-$ & 102 & 130 & & 11 & 26 \\
$65-$ & 124 & 142 & & 26 & 35 \\
$75-$ & 104 & 101 & & 23 & 38 \\
$85-$ & 27 & 15 & & 12 & 5 \\
$\geqslant 95$ & 1 & 1 & & &
\end{tabular}

\section{Discussion}

The difficulties of investigating the epidemiology of peptic ulcer disease were summarised by Strudevant in 1976. ${ }^{17}$ Depending on how the frequency of ulcers and ulcer scars is determined (number of perforations, number of hospital admissions of patients with ulcers, or number of ulcers in a population) different views of the disease emerge. The results of different studies also show the medical, social, and geographical situation of the population at the time of the particular investigation. The accuracy of the basic population registers and hospital records influences the results. Also, one study cannot serve as a control to another.

Death from a perforated gastric ulcer was common during 1840-1900 among young women. ${ }^{1}$ This trend later changed to a predominance of death from perforated duodenal ulcer among men. ${ }^{18}$ Several investigators have shown a steady increase in the incidence of perforation with rising age among women, ${ }^{7} 1920$ whereas the rate of perforation among elderly men has remained unchanged over time. Among younger men the rate of perforation has declined. ${ }^{7}$ Whereas all patients with perforated peptic ulcers are admitted to hospital and stable rates of admission were shown during the 10 years $1970-80$ for patients with perforated duodenal and gastric ulcers, the rates of admission for uncomplicated duodenal and gastric ulcers have declined considerably. ${ }^{34}$ This may be explained by improved effect of treatment or availability of medical care, or both. In our study there were 27 patients ( 14 men and 13 women) with perforated ulcers. Thus the total rate of perforation was only $2 \cdot 4 \%$ of all patients with ulcers diagnosed in Gothenburg during 1985.

International comparisons between population studies are valid only when thorough knowledge of the populations exists and the biostatistical calculations are performed in a corresponding way. Nevertheless, comparison remains difficult because of dissimilarities in the distribution of different age groups in basic populations. This is especially important in studies on peptic ulcer disease, an essential feature of which is an age specific increase in incidence. ${ }^{21-25}$ The homogeneous and well defined population in northern Europe has encouraged epidemiological

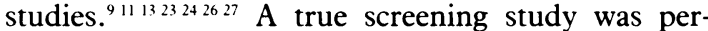
formed by Ihamäki et al, who investigated with gastroscopy a group of 358 people selected at random from the population and matched for age and sex with relatives of patients with gastric cancer. ${ }^{13} \mathrm{Kiil}$ and Andersen showed that endoscopy is significantly more efficient than a barium meal in diagnosing ulcers. ${ }^{27}$ Gastroscopy was also used by Kiaer $e t$ al $^{11}$ and Permutt and Cello, ${ }^{12}$ whereas other Scandinavian studies including those of Bonnevie from Copenhagen relied on hospital admissions and barium meal. ${ }^{23}{ }^{24}$ These
Scandinavian studies are difficult to compare with our investigation of 1121 ulcers diagnosed by gastroscopy. In our study 925 of the patients were outpatients, reflecting the fact that hospital admission has become less important when diagnosing and treating peptic ulcer.

Rapid changes in social environment were formerly considered to be responsible for the considerable changes in age and sex dependent incidence of peptic ulcer disease that took place during the nineteenth century. ${ }^{28}$ This could also be described as development of peptic ulcer disease dependent on birth cohort. ${ }^{25} \mathrm{~A}$ steady increase in the proportion of elderly patients with peptic ulcers has been noted: $22 \%$ of 1800 successive admissions for peptic ulcer during 1941-7 in New York were of patients aged over $69^{29}$; Elashoff and Grossman found that $36 \%$ of all patients with duodenal ulcers were aged over 60 years, ${ }^{5}$ as were nearly a third of the patients with duodenal ulcers in the 1977-80 San Francisco study. ${ }^{12}$ In our study $403(54 \%)$ of the diagnoses in men and $393(60 \%)$ of the diagnoses in women applied to patients aged over $60 ; 109(48 \%)$ of all new peptic ulcers in men affected patients over 60 , and the corresponding figure for women was 129 $(57 \%)$. This is a larger proportion of elderly patients than in any previous study, partly because of the large number of elderly people in the population but also because of the high age specific incidence.

Studies from York show an incidence of symptoms of ulcers of 2 per $1000^{30}$; in the Faeroe Isles and Copenhagen the incidence of duodenal ulcer in men aged $60-69$ was $2 \cdot 4$ and 3 per 1000 , respectively. ${ }^{1124}$ In our study the corresponding figure for new duodenal ulcers was 1.04 per 1000 men, whereas the age group 75-79 years showed the highest incidence of all types of new ulcer (table IV). In the 1981 United States national

TABLE IV - Ulcers diagnosed for first time among patients aged 75-79 in Gothenburg, 1985

\begin{tabular}{lcc}
\hline Type of ulcer & Sex of patient & No of ulcers per 1000 \\
\hline Duodenal & $\{$ Men & $1 \cdot 9$ \\
Gomen & $0 \cdot 88$ \\
Gastric & Men & 0.95 \\
Prepyloric & Women & $1 \cdot 17$ \\
& Men & $0 \cdot 95$ \\
Women & 0.68 \\
\hline
\end{tabular}

health survey more women than men reported ulcers. ${ }^{31}$ Examining the data from the National Center for Statistics, Kurata et al suggested that there may have been a real increase in the prevalence of peptic ulcers among women because of either an increase in incidence or an increase in duration of disease. ${ }^{32} \mathrm{~A}$ dramatic increase in the predominance in women of ulcers in the corpus area and the rising age of women with gastric ulcers was also reported from New Zealand in $1982 .{ }^{8}$ According to the United States national disease and therapeutic index the rate of medical attendances from symptoms suggesting gastric ulcer from 1958 to 1984 decreased in men and increased slightly in women, and the ratio of men to women decreased for both gastric and duodenal ulcers. ${ }^{33}$

In our study the ratio of men to women for the incidence of new ulcers at 40-50 years was 1:1 (fig 2). In Sweden the employment rate among women aged 20 64 is $83 \%$, and this could in certain respects reduce the sex difference with respect to lifestyle. The 1945 birth cohort of the population of Gothenburg showed a ratio of male to female smokers of $1: 1$, whereas the proportion of smokers was much smaller among older women than older men.

The continuously increasing proportion of women smokers in Gothenburg and the growing number of elderly people (in 1985, $18 \%$ of the Swedish population 
was aged over 65) could further exaggerate the future incidence of peptic ulcer in women. The high incidence of ulcer diagnosed for the first time in women over 65 compared with men could partly depend on the fact that $7 \cdot 5 \%$ of Gothenburg men born during 1901-7 had previously undergone surgery for peptic ulcer. ${ }^{34} \mathrm{~A}$ still higher proportion must have developed peptic ulcer earlier in life.

Age dependent changes in gastric acid secretion, pepsin secretion, or defective mucosal protection and unfavourable delay in gastric emptying or duodenogastric reflux may all be of aetiological importance for the development of peptic ulcer. The age dependent changes in the gastric acid secreting area $a^{35}$ differ between healthy people and patients with peptic ulcers, and a significant increase in output of gastric acid with increasing age was shown in women with normal gastric mucosa when the acid output was expressed in relation to fat free body weight. ${ }^{36}$ Earlier assumptions of decreasing acid secretion with increasing age did not take into account the morphological state of the mucosa or of calculated fat free body weight. ${ }^{37}$ Further reports have appeared of benign gastric ulceration in association with pernicious anaemia - that is, in achlorhydric patients. ${ }^{38} 39$

With regard to secretion of pepsin Krenz and Jablonovski found no age dependent changes in pepsin production in their comparative studies. ${ }^{40} \mathrm{As}$ far as we know the role of cytoprotective factors such as secretion of gastric sodium hydroxide, secretion of mucus, and production of intragastric-intracellular prostaglandins remains to be studied with respect to age dependent variations.

The absence of abdominal pain in elderly patients, which is equally common among patients with duodenal and gastric ulcers, ${ }^{12} 41$ probably explains the large proportion (over half) of elderly patients presenting with a serious complication at the time of first diagnosis of the ulcer ${ }^{3042}$ : in our study $222(20 \%)$ patients with peptic ulcer presented with bleeding and $27(2 \cdot 4 \%)$ with perforation. We have shown a high incidence of peptic ulcer in women and in elderly patients. The incidence of peptic ulcer disease does not seem to be declining in contrast with the mortality, rate of surgical intervention, and hospital admissions. The low rate of perforation probably reflects the current treatment of peptic ulcer disease with $\mathrm{H}_{2}$ receptor antagonists and presumably also the high availability of endoscopy.

We thank Professor Tore Scherstén, who supervised the planning of this investigation and encouraged us while it was going on; $\mathrm{Mr}$ Walter Sund, Ms Birgitta Hillvärn, and $\mathrm{Mr}$ Mats Andrén, who computerised the material; and Dr Marcia Skogh for revising the text.

1 Susser M, Stein Z. Civilisation and peptic ulcer. Lancet 1962;i:115-9.

2 Kurata JH, Elashoff JD, Haile BM, Honda GD. A reappraisal of time trends in ulcer hospitalization and mortality rates. Am $\mathcal{F}$ Public Health 1983;73: 1066-72.

3 Gustavsson S, Kelly KA, Melton LJ III, Zinsmeister AR. Trends in peptic ulcer surgery. A population-based study in Rochester, Minnesota, 1956 1985. Gastroenterology 1988:94:688-94.

4 Kurata JH, Honda GD, Frankl H. Hospitalization and mortality rates for peptic ulcers: a comparison of a large HMO and US data. Gastroenterology 1982;83:1008-16.

5 Elashoff JD, Grossman MI. Trends in hospital admissions and death rates for peptic ulcer in the United States from 1970-1978. Gastroenterology $1980 ; 78: 280-5$

6 Vogt TM, Johnson RE Recent changes in the incidence of duodenal and gastric ulcer. Am f Epidemiol 1980;111:713-20.

7 Walt R, Katschinski B, Logan R, Ashley J, Langman MJS. Rising frequency of ulcer perforation in elderly people in the United Kingdom. Lance 1986 ; $1: 489-92$.

8 Lee SP. Rising female predominance in incidence of gastric ulcer. Br Med $\mathcal{J}$ 1982;285:853-4.

9 Østensen H, Burhol PG, Bonnevie O, Bolz HD. Changes in the pattern of peptic ulcer disease in the northern part of Norway between 1946 and 1981 Scand F Gastroenterol 1982;17:1073-6.

10 Kurata JH, Corby ED. Current peptic ulcer time trends. An epidemiological profile. $\mathcal{F}$ Clin Gastroenterol 1988;10:259-68.

1 Kiaer T, Roin J, Dahl-Niclassen S, Bonnevie O. Epidemiological aspects of peptic ulcer disease on the Faroe Islands. Scand $\mathcal{F}$ Gastroenterol 1985;20: $1157-62$

12 Permutt RP, Cello JP. Duodenal ulcer disease in the hospitalized elderly patient. Dig Dis Sci 1982;27:1-6.

13 Ihamäki T, Varis K, Siurala M. Morphological, functional and immunological state of the gastric mucosa in gastric carcinoma families. Comparison with state of the gastric mucosa in gastric carcinoma families. Comparison with
computermatched family sample. Scand f Gastroenterol 1979;14:801-12.

14 Lehmann EL. Testing statistical hypotheses. New York: Wiley, 1959:140-3.

15 Maxwell AE. Analyzing qualitative data. London: Methuen, 1961.

16 Odén A, Wedel H. Arguments for Fischer's permutation tests. Annals of Statistics 1975;3:518-20

17 Strudevant RAL. Epidemiology of peptic ulcer. Am J Epidemiol 1976;104 9-14

18 Fry J. Peptic ulcer: a profile. BrMed $\mathcal{f}$ 1964;ii:809-12.

9 MacKay C. Prevalence of peptic ulcer and its complications. Scott Med $\mathcal{f}$ $1977 ; 22: 287-9$.

20 Langman MJS. The tide of peptic ulcer. Scand f Gastroenterol [Suppl] 1980;63:149-56.

21 Palmer ED. The cyclic dynamism of the incidence and complications of ulcer disease. Surg Gynecol Obstet 1979;130:709-20.

22 Kurata JH, Haile BM. Epidemiology of peptic ulcer disease. Clinics in Gastroenterologv 1984;13:289-307.

23 Bonnevie $O$. The incidence of gastric ulcer in Copenhagen county. Scand $\mathcal{f}$ Gastroenterol 1975;10:231-9.

24 Bonnevie $O$. The incidence of duodenal ulcer in Copenhagen county. Scand $\mathcal{f}$ Gastroenterol 1975;10:385-93.

25 Sonnenberg A. Geographical and temporal variations in the occurrence of peptic ulcer disease. Scand f Gastroenterol [Suppl] 1985;110:11-24

26 Bonnevie O. Peptic ulcer in Denmark. Scand $\mathcal{f}$ Gastroenterol [Suppl] 1980;63:163-74

27 Kiil J, Andersen D. X-ray examination and/or endoscopy in the diagnosis of gastroduodenal ulcer and cancer. Scand $\mathcal{F}$ Gastroenterol 1980;15:39-43.

8 Susser $M$. Causes of peptic ulcer. A selective epidemiological review. J Chronic Dis 1967;20:435-56.

29 Rafsky HA, Weingarten $M$, Krieger ChI. Onset of peptic ulcer in the aged. FAMA 1948;136:739-42.

30 Pulvertaft CN. Experiences with peptic ulcer in elderly men in York: Age Ageing 1972;1:24-9.

31 National Center for Health Statistics. Current estimates from the national health interview survey: United States 1979. Hyattsville, Maryland: Public Health interview survey: United States 1979. Hyattsville, Maryland: Public Health statistics series 10 No 136.))

32 Kurata JH, Haile BM, Elashoff J. Sex difference in peptic ulcer disease. Gastroenterology 1985;88:96-100.

33 Sonnenberg A. Changes in physician visits for gastric and duodenal ulcer in the United States during 1958-1984 as shown by national disease and therapeutic index (NDTI). Dig Dis Sci 1987;32:1-7.

34 Mellström D, Rundgren $\AA$. Long-term effects after partial gastrectomy in elderly men. A longitudinal population study of men between 70 and 75 years of age. Scand F Gastroenterol 1982;7:433-9.

35 Tatsuta $M$, Okuda S. Age-related changes in the acid-secreting area in patient with duodenal ulcer. Endoscopy 1983;15:243-5.

36 Kekki M, Samloff IM, Ihamäki T, Varis K, Siurala M. Age- and sex-related behaviour of gastric acid secretion at the population level. Scand $\mathcal{f}$ Gastroenterol 1982;17:737-43.

37 Baron JH. Studies of basal and peak acid output with an augmented histamine test. Gut 1963;4:136-44.

38 Logan RFA, Gillon J, Logan ECM. Benign gastric ulceration with pernicious anaemia. BrMed f 197.9; i:308

39 Reid J, Taylor TV, Holt S, Heading RC Benign gastric ulceration in pernicious anemia. Dig Dis Sci 1980;25:148-9.

$40 \mathrm{Krenz} \mathrm{K}$, Jablonovski H. Functional and histological changes with age. In Hellemans J, Vantrappen G, eds. Gastrointestinal tract disorders in the elderly. New York: Churchill Livingstone, 1984:62-84

41 Clinch D, Baneriee AK, Ostick G. Absence of abdominal pain in elderly patients with peptic ulcer. Age Ageing 1984;13:120-3.

42 Colin-Jones DG. Problems of peptic ulceration in the elderly. Postgrad Med $\mathcal{f}$ 1975;51(suppl 5):41-5

(Accepted 10 August 1989)

\section{ONE HUNDRED YEARS AGO}

The method of carrying a man by the arms and legs, with the face downwards, has been discountenanced in the army. In the control of violence the police have generally to deal with excitement due to heavy drinking, and this is a condition in which a severe struggle may produce fatal results. Acute dilatation of the heart, with rapid, weak pulse, has been repeatedly observed in acute alcoholism, and with the additional difficulties of respiration and circulation produced by the "frog's march," cardiac thrombosis and pulmonary apoplexy may be produced. The man Mahony's death was attributed "to syncope, due to disease of the lungs, and the violent exercise which the man had gone through." Drunken persons have often died while in charge of the police authorities; for the credit of the force, as well as for the safety of the unfortunate victims, stretchers should be employed in the conveyance and treatment of cases of violent drunkenness. The police are supplied with, and trained in the use of wheeled stretchers and litters by the St. John Ambulance Association; and it is to be hoped that improved electrical communication will soon render ambulances as quickly available in cases of emergency as fire escapes and engines at the present time. (British Medical Fournal 1889;1:726) 